\title{
ANALISIS METODE PEMBELAJARAN S3D TERHADAP PENGEMBANGAN SOFT SKILL MAHASISWA
}

\author{
Wahyudhi Sutrisno \\ Jurusan Teknik Industri, Fakultas Teknologi Industri, Universitas Islam Indonesia \\ Jl. Kaliurang Km 14,5 Sleman \\ E-Mail :075220417@uii.ac.id
}

\begin{abstract}
ABSTRAK
Universitas merupakan salah satu penghasil calon tenaga kerja yang mempunyai pengaruh penting dalam menentukan keberhasilan dan kesuksesan tenaga kerja dalam meniti jenjang karirnya. Universitas diharapkan dapat menghasilkan calon tenaga kerja berkualitas, siap pakai, serta mempunyai hard skill dan soft skill. Penelitian ini bertujuan untuk menganalisis metode pembelajaran program Student Soft Skill Development (S3D) yang dilaksanakan di Fakultas Teknologi Industri Universitas Islam Indonesia. S3D merupakan salah satu program yang diterapkan dengan tujuan untuk mengembangkan soft skill yang dimiliki oleh mahasiswa. Penelitian ini menggunakan metode literature review dimana peneliti membaca, memahami, dan membandingkan literatur dari berbagai macam sumber dengan obyek yang diteliti. Kesimpulan dari penelitian ini adalah metode pembelajaran S3D dapat mengembangkan soft skill mahasiswa karena metodenya sesuai dengan teori dan hasil penelitian lainnya mengenai pendidikan soft skill.
\end{abstract}

Kata kunci: Universitas; Tenaga Kerja; Metode Pembelajaran; Soft Skill

\section{S3D LEARNING METHOD ANALYSIS FOR STUDENT SOFT SKILL DEVELOPMENT}

\begin{abstract}
The university is one of the producers of prospective workers who have an important influence in determining the success of the workforce in pursuing their career path. The university is expected to be able to produce qualified workforce candidates, ready to use, and have hard skills and soft skills. This study aims to analyze the learning methods of the Student Soft Skill Development (S3D) program conducted at Faculty of Industrial Technology, Islamic University of Indonesia. S3D is one of the programs implemented with the aim of developing soft skills possessed by students. This study uses the literature review method where the researcher reads, understands, and compares literature from various sources with the object under study. The conclusion of this research is S3D learning method is in accordance with the theory and the results of other studies regarding soft skills education.
\end{abstract}

Keywords: Universities; Labor; Learning Methods; Soft Skills

\section{PENDAHULUAN}

Penilaian kinerja tenaga kerja merupakan kegiatan yang dilakukan manajer untuk mengevaluasi perilaku dan prestasi

kebijaksanaan perusahaan selanjutnya (Hasibuan, 2000). Komponen kunci penilaian kinerja dapat dilihat pada kerja pegawai serta menetapkan Gambar 1.

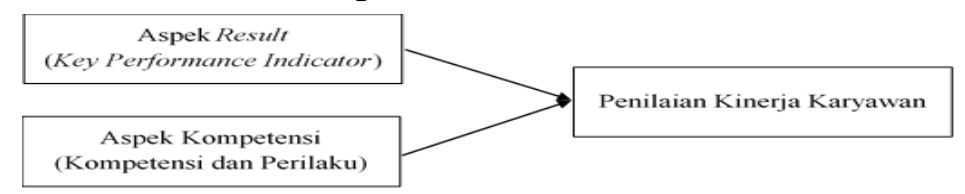

Gambar 1. Komponen Kunci Penilaian Kinerja

(Sumber: Antariksa, 2011) 
Tabel 1. Faktor Penentu Kesuksesan (Sumber: The Millionaire Mind, 2000)

\begin{tabular}{c|c}
\hline No & Faktor Penentu Kesuksesan \\
\hline 1 & Bersikap jujur kepada semua orang \\
2 & Mempunyai disiplin yang baik \\
3 & Pintar bergaul \\
4 & Mempunyai pasangan hidup yang mendukung \\
5 & Bekerja lebih keras daripada orang lain \\
6 & Mencintai karier/pekerjaan \\
7 & Memiliki kualitas kepemimpinan yang baik dan kuat \\
8 & Memiliki semangat/kepribadian yang sangat kompetitif \\
9 & Mengatur hidup dengan sangat baik \\
10 & Memiliki kemampuan untuk menjual ide/produk \\
\hline
\end{tabular}

Seorang karyawan yang ingin sukses dalam karir, dan atau mendapatkan penilaian kinerja yang tinggi dari perusahaannya haruslah mempunyai keahlian di kedua komponen kunci penilaian kinerja yaitu dalam aspek result dan aspek kompetensi.

Key performance indicator merupakan ukuran berskala dan kuantitatif yang digunakan oleh perusahaan untuk mengevaluasi kinerja karyawan dalam tujuan mencapai target perusahaan (Banerjee dan Buoti, 2012). Pengertian kompetensi menurut Undang-undang Republik Indonesia Nomor 13 Tahun 2003 tentang ketenagakerjaan, menyatakan bahwa kompetensi kerja adalah kemampuan kerja setiap individu yang mencakup aspek pengetahuan, keterampilan, dan sikap kerja yang sesuai dengan standar yang ditetapkan.

Stanley (2000) melakukan penelitian mengenai faktor - faktor utama yang menentukan kesuksesan seseorang. Peringkat $1 \mathrm{~s} / \mathrm{d} 10$ faktor - faktor utama yang menentukan kesuksesan dapat dilihat pada Tabel 1.

Berdasarkan penelitian tersebut, dapat kita ketahui bahwa Soft Skill mempunyai peranan yang penting bagi kesuksesan seseorang.

Universitas merupakan salah satu penghasil calon tenaga kerja yang mempunyai pengaruh penting dalam menentukan keberhasilan dan kesuksesan tenaga kerja.
Universitas diharapkan dapat menghasilkan calon tenaga kerja berkualitas, siap pakai, serta mempunyai keahlian teknis (hard skill) dan keahlian manajerial (soft skill).

Penelitian ini bertujuan untuk menganalisis metode pembelajaran program Student Soft Skill Development (S3D) yang dilaksanakan di Fakultas Teknologi Industri Universitas Islam Indonesia. S3D merupakan salah satu program yang diterapkan di FTI UII dengan tujuan untuk mengembangkan soft skill yang dimiliki oleh mahasiswa.

\section{METODOLOGI}

Metode penelitian pada penelitian ini menggunakan metode literature review. Literature review merupakan suatu metode dimana peneliti membaca, memahami, dan membandingkan literatur dari berbagai macam sumber dengan obyek yang diteliti. Objek penelitian adalah metode pembelajaran program Student Soft Skill Development (S3D) FTI UII.

Penelitian ini menggunakan data sekunder yaitu data sudah tersedia dan dapat diperoleh dengan cara membaca, melihat dan mendengarkan (Jonathan, 2006). Validitas data menggunakan metode triangulasi sumber dimana data yang telah diperoleh, kemudian dideskripsikan, dikategorisasikan, dan dicari pandangan yang sama (Sugiyono, 2011). Data dikatakan valid apabila berasal dari tiga sumber yang memiliki kesamaan. 
Kajian literatur pada penelitian ini akan dibagi menjadi dua bagian yaitu:

1) Penelitian tentang pentingnya soft skill bagi mahasiswa.

2) Penelitian tentang metode pembelajaran $\mathrm{S} 3 \mathrm{D}$

\section{HASIL DAN PEMBAHASAN}

\subsection{Penelitian tentang pentingnya soft skill} bagi mahasiswa

Soft skill merupakan skills yang berkaitan dengan hubungan antar manusia, seperti bagaimana melakukan penyelesaian konflik, memahami personal dynamics, dan melakukan negosiasi (Sucipta, 2009). Sedangkan menurut Widhiarso (2009), Soft skills adalah seperangkat kemampuan yang mempengaruhi bagaimana seseorang berinteraksi dengan orang lain. Contoh soft skills adalah kemampuan berkomunikasi, leadership, kerjasama tim dan lain-lain. Beberapa penelitian tentang soft skill yang pernah dilakukan sebelumnya, antara lain:

1) Mitsubishi Research Institute pernah melakukan penelitian pada tahun 2000 mengenai faktor - faktor yang menentukan kesuksesan lulusan (Endrotomo, 2010). Hasilnya menyimpulkan bahwa kesuksesan lulusan ternyata paling banyak ditentukan oleh kematangan emosi dan sosial sebesar $40 \%$, diikuti oleh proses networking yang dijalin sebesar $30 \%$, $20 \%$ oleh kemampuan akademis dan terakhir sebesar $10 \%$ oleh kemampuan finansial yang dimiliki.

2) Berdasarkan Survey National Association of Colleges and Employee (NACE) yang dilakukan pada tahun 2002, terdapat 19 kemampuan yang diperlukan di pasar kerja (Elfindri dkk, 2011). Kemampuan yang diperlukan dipasar kerja dapat dilihat dalam Tabel 2. Dari Tabel 2 dapat diketahui bahwa 16 dari 19 kemampuan yang diperlukan dipasar kerja adalah aspek soft skills, bahkan rangking 7 teratas ditempati oleh aspek soft skills.
3) Penelitian yang dilakukan oleh Watts $M$ dan Watts R. K, (2008) menemukan bahwa dalam era yang kompetitif saat ini, maka kesuksesan seorang professional ditentukan oleh soft skill sebesar $85 \%$ sedangkan hard skill hanya $15 \%$. Penelitian juga menunjukkan bahwa banyak perusahaan yang ingin merekrut, mempertahankan, dan mempromosikan tenaga kerja yang dapat diandalkan, banyak akal, beretika, mandiri, memiliki komunikasi yang efektif, mau bekerja dan belajar serta memiliki sikap positif.

4) Penelitian dilakukan oleh Rashidi (2018) menyatakan bahwa Sistem pendidikan harus mengarah pada kelayakan kerja dan memastikan kualitas dalam pendidikan untuk mengurangi persentase pengangguran. Ada kesenjangan besar dalam kualifikasi tenaga kerja yang dibutuhkan dengan kualitas lulusan yang tersedia. Kesenjangan ini dapat diatasi dengan soft skill. Soft skill mendorong hubungan yang lebih baik di antara orang-orang dan membantu siswa untuk menjadi orang yang sukses.

5) Marchand dkk (2005) menemukan bahwa uang jutaan dolar terbuang oleh institusi dan masyarakat karena faktor minimnya produktivitas, pelayanan kesehatan, kecelakaan kerja dan pegawai yang absen dalam bekerja. Pendukung utama dari sekian indikator tersebut adalah gaya hidup individu yang tidak sehat. University of Central Florida memasukkan tema gaya hidup sehat ini sebagai target pengembangan soft skills bagi mahasiswa mereka. Topik yang diangkat dalam pengembangannya memuat nutrisi, manajemen stres, pengelolaan waktu, cultural diversity, dan penyalahgunaan obat terlarang. Hasil penelitian menunjukkan bahwa gaya hidup yang sehat mempengaruhi tingginya ketahanan, fleksibiltas dan konsep diri yang sehat yang mempengaruhi tingginya partisipasi dalam komunitas. 
Tabel 2. Kemampuan yang Diperlukan di Pasar Kerja (Sumber: Elfindri dkk, 2011)

\begin{tabular}{c|c|c}
\hline Kemampuan & Klasifikasi Skill & Rangking \\
\hline Komunikasi & Soft Skill & 1 \\
Kejujuran/integritas & Soft Skill & 2 \\
Bekerjasama & Soft Skill & 3 \\
Interpersonal & Soft Skill & 4 \\
Etos kerja yang baik & Soft Skill & 5 \\
Motivasi/inisiatif & Soft Skill & 6 \\
Mampu beradaptasi & Soft Skill & 7 \\
Analitikal & Kognitif hard skill & 8 \\
Komputer & Psikomotor hard skill & 9 \\
Organisasi & Soft Skill & 10 \\
Orientasi detail & Soft Skill & 11 \\
Kepemimpinan & Soft Skill & 12 \\
Percaya diri & Soft Skill & 13 \\
Sopan / beretika & Soft Skill & 14 \\
Bijaksana & Soft Skill & 15 \\
Indeks prestasi >3,00 & Kognitif hard skill & 16 \\
Kreatif & Soft Skill & 17 \\
Humoris & Soft Skill & 18 \\
Kemampuan Entreprenership & Soft Skill & 19 \\
\hline
\end{tabular}

6) Robles (2012) dalam penelitiannya menyimpulkan eksekutif bisnis menganggap bahwa soft skill merupakan atribut yang sangat penting dalam pelamar pekerjaan. Pengusaha menginginkan karyawan baru untuk memiliki soft skill yang kuat, serta hard skill. Studi ini mengidentifikasi 10 soft skill teratas yang dianggap paling penting oleh eksekutif bisnis yaitu integritas, komunikasi, kesopanan, tanggung jawab, keterampilan sosial, sikap positif, profesionalisme, fleksibilitas, kerja tim, dan etos kerja.

7) Penelitian yang dilakukan oleh Center for enterpreneurship education and development, Halifax, pada tahun 2004. Mereka mengadakan survei di Amerika, Canada dan Inggris. Hasil penelitian menemukan 23 atribut soft skill yang dominan dibutuhkan dilapangan pekerjaan yaitu inisiatif etika atau integritas, berfikir kritis, kemauan belajar, komitmen, motivasi, bersemangat, dapat diandalkan, komunikasi lisan, kreatif, kemampuan analitis, dapat mengatasi stress, manajemen diri, menyelesaikan persoalan, dapat meringkas, berkooperasi, fleksibel, kerja dalam tim, mandiri, mendengarkan, tangguh, berargumen logis, manajemen waktu.

8) Penelitian yang dilakukan oleh Neff dan Citrin, yang hasilnya mereka tulis dalam sebuah buku berjudul Lesson from The Top. Pada tahap pertama, peneliti meminta kepada sekitar 500 orang (CEO dari berbagai perusahaan, LSM, dan dekan / rektor perguruan tinggi) agar mereka menominasikan 50 nama orangorang yang menurut mereka tersukses di Amerika. 50 nama yang didapatkan antara lain yaitu Jack Welch (General Electric), Bill Gates (Microsoft), Andy Grove (Intel), Lou Gerstner (IBM), dan Michael Dell (Dell Computer). Tahap berikutnya, peneliti mewawancarai 50 orang terpilih tersebut satu-per-satu untuk mengetahui rahasia sukses para pengusaha tersebut. Didapatkan 10 kiat yang menurut 50 orang tersebut paling menentukan kesuksesan mereka. Ternyata dari sepuluh kiat sukses tersebut tak satupun menyebut 
pentingnya memiliki keterampilan teknis alias hardskills sebagai persyaratan untuk sukses di dunia kerja. 50 orang tersebut seolah sepakat bahwa yang paling menentukan kesuksesan mereka bukanlah keterampilan teknis, melainkan kualitas diri yang termasuk dalam kategori soft skills. 10 kiat sukses 50 orang tersukses di Amerika tersebut yaitu passion, intelligence and clarity of thinking, great communication skills, high energy level, egos in check, inner peace, capitalizing early life experience, strong family lifes, positive attitude dan focus on "doing the right things right".

9) Penelitian yang dilakukan oleh Shuayto (2012) menemukan bahwa banyak para lulusan perguruan tinggi tidak memiliki kemampuan untuk menerapkan pengetahuan yang telah mereka peroleh dari kampus, untuk diterapkan pada dunia kerja. Ketidakmampuan ini disebabkan karena mereka tidak mempunyai soft skill yang dapat membuat mereka beradaptasi dengan lingkungan kerja.

10) Penelitian tentang Critical skill dan skill gap yang dilakukan oleh University of Missouri-St. Louis pada tahun 2012. Critical skill adalah keterampilan penting yang dibutuhkan seseorang untuk melakukan pekerjaan pada tingkat kinerja yang tinggi. Sedangkan skill gap didefinisikan sebagai kesenjangan yang signifikan antara keterampilan yang dibutuhkan untuk melakukan pekerjaan dengan baik dengan keterampilan yang dimiliki saat memasuki dunia kerja. Hasil penelitiannya dapat dilihat pada Tabel 3. Penelitian juga menemukan bahwa kesenjangan skill menyebabkan produktivitas dan kinerja karyawan berkurang. Kesenjangan skill disebabkan oleh kurangnya pengalaman, kurangnya kesadaran, kesenjangan lingkungan akademik dengan bisnis, dan prioritas yang tidak pantas. Selain itu juga terdapat kurangnya waktu dan kecepatan perubahan. Menurut penelitian ini juga, kesenjangan skill ini dapat ditutupi oleh universitas dengan berbagai cara, salah satunya adalah dengan mengadakan Business communications skills training.

11) Profesor M.S. Rao, pendiri MSR Leadership Consultants, India, melakukan penelitian yang berjudul Enhancing employability in engineering and management students through soft skills, Tujuan dari penelitiannya adalah untuk menjembatani kesenjangan antara kampus dan industri melalui teknik dan manajemen dan siswa untuk meningkatkan kinerja mereka. Penelitian menemukan bahwa pengajaran dan pelatihan metode yang tepat akan dapat memengaruhi dan memotivasi mahasiswa untuk memperoleh keterampilan dan kemampuan secara efektif. Berdasarkan hasil penelitian yang dilakukan, peneliti mempunyai beberapa saran buat universitas, antara lain memberikan konseling karir dan mentoring kepada mahasiswa, mengembangkan bakat mahasiswa dan mengasah kemampuan mahasiswa serta menyelenggarakan program pelatihan soft skill kepada mahasiswa secara teratur.

12) Mahasiswa pada umumnya percaya bahwa mereka harus giat belajar agar mendapatkan IPK tinggi karena perusahaan menginginkan pelamar dengan nilai akademik yang baik. Namun berdasarkan hasil penelitian yang dilakukan oleh Salas (2012) menunjukkan bahwa soft skill seperti komunikasi, kerja tim, kepemimpinan adalah atribut yang paling dicari dan dibutuhkan oleh perusahaan dalam proses seleksi penerimaan karyawan.

13) National Association of Colleges and Employers (NACE) pada akhir 2017 melakukan penelitian mengenai atribut kunci pada resume pelamar yang menarik perusahaan (Gray dan Koncz, 2017). Hasil dari penelitian ini adalah pelamar yang sedang melakukan pencarian kerja dan ingin mengesankan pengusaha dengan resume maka mereka 
Tabel 3. Top 10 Critical Skills and Skill Gaps 2012

(Sumber: http://www.umsl.edu/divisions/business/files/pdfs/skillsgap13_14.pdf)

\begin{tabular}{c|c}
\hline Critical Skills & Skill Gaps \\
\hline Oral Communication & Written Communication \\
Active Listening & Leadership \\
Written Communication & Critical/Analytical Thinking \\
Teamwork & People Management \\
Prioritization and Focus & Strategic Planning \\
Time Management & Oral Communication \\
Analytical Thinking & Active Listening \\
External Customer Service & Prioritization and Focus \\
Decision Making & Time Management \\
Internal Customer Service & Change Management \\
\hline
\end{tabular}

harus menekankan kemampuan mereka dalam menyelesaikan masalah dan kemampuan bekerja sebagai bagian dari tim. Setelah itu keterampilan komunikasi tertulis, kepemimpinan, dan etos kerja yang kuat juga merupakan atribut yang sangat dihargai yang ingin dilihat oleh pemberi kerja pada bukti resume.

14) Mackes (2017) berdasarkan penelitiannya menyatakan bahwa mahasiswa yang memasuki pasar kerja sering merasa sulit untuk menunjukkan soft skill mereka pada aplikasi dan resume dan dalam wawancara padahal akuisisi dan penerapan soft skill inilah yang dapat membuat semua perbedaan untuk sukses di tempat kerja. Mackes juga menemukan bahwa lebih dari 70 persen perusahaan secara konsisten mengidentifikasi kepemimpinan, kerja tim, kemampuan komunikasi tertulis, penyelesaian masalah dan etos kerja sebagai atribut resume utama yang mereka harapkan ada pada resume pelamar.

15) Penelitian yang dilakukan oleh Mathur (2017) menyatakan bahwa banyak perusahaan yang mengeluhkan tentang kurangnya soft skill pada lulusan dibidang teknik. Perkembangan teknologi yang cepat dan peran penting komputer membuat teknisi terlibat dalam banyak kegiatan organisasi, berkomunikasi dengan pengguna di semua unit fungsional, sehingga ini membutuhkan keterampilan komunikasi dan presentasi yang sangat baik.

Hasil penelitian - penelitian tersebut membuktikan bahwa soft skill merupakan salah satu faktor penting yang menentukan keberhasilan dan atau kesuksesan mahasiswa ketika memasuki dunia kerja. Oleh karena itu sebaiknya Universitas melengkapi mahasiswanya dengan keahlian soft skill melalui program - program pengembangan soft skill.

\subsection{Penelitian tentang metode pembelajaran S3D}

Metode pembelajaran Student Soft Skill Development S3D diterapkan dengan membagi menjadi tiga sesi yaitu:

\section{1) Why $S 3 D$}

Pada sesi pertama ini, mahasiswa diberikan informasi mengenai pentingnya mereka mengikuti program S3D ini. Program S3D dilaksanakan supaya mahasiswa dapat mengetahui pentingnya soft skill dalam mencapai kesuksesan baik ketika masih kuliah ataupun ketika memasuki dunia kerja. Selain itu juga, pada sesi ini mahasiswa diajarin mengenai cara mengembangkan soft skill yang telah dimiliki dan atau yang akan dibutuhkan. Metode ini sesuai dengan pendapat Schulz (2008) yang menyatakan bahwa langkah pertama dalam meningkatkan soft skill siswa 
adalah dengan meningkatkan kesadaran mereka tentang pentingnya soft skill dan konsekuensi yang mungkin timbul apabila mereka tidak mempunyai soft skill yang cukup. Hal ini juga diperkuat dengan penelitian yang dilakukan oleh Tseng (2018) yang menyimpulkan bahwa soft skill penting bagi proses pembelajaran siswa serta potensi bagi siswa untuk sukses dalam karirnya.

Soft skill adalah ketrampilan yang harus dilakukan secara terus menerus agar bisa dimiliki oleh mahasiswa. Dalam sesi ini juga, diberikan contoh orang-orang sukses beserta skill yang dimilikinya, tujuannya adalah untuk memotivasi peserta. Hal ini sesuai dengan penelitian-penelitian yang telah dilakukan sebelumnya, yaitu mahasiswa yang diikutkan program pengembangan soft skill sebaiknya diberikan informasi mengapa mereka dimasukkan dalam program ini, dengan tujuan mereka bisa aktif terlibat dalam program.

\section{2) Who am I}

Pada sesi ini, mahasiswa peserta S3D diminta untuk mengenal diri mereka masingmasing sehingga diharapkan mahasiswa dapat mengetahui peran dan kontribusi mereka dalam kehidupan. Mengenal diri sendiri terutama berkaitan dengan kelebihan dan kekurangan yang dimiliki. Mahasiswa dapat mengetahui kelebihan dan kekurangan yang dimiliki berdasarkan tiga cara yaitu, dengan melakukan intropeksi diri, mengamati perilaku orang lain dan yang terakhir adalah dengan meminta umpan balik dari orang lain.

Tujuan dari sesi ini adalah agar peserta mengerti kelebihan yang mereka miliki, bagaimana memanfaatkan kelebihan tersebut untuk mendapatkan tujuan yang ingin mereka raih. Kelebihan bukan hanya berdasarkan pendapat mereka, tapi juga berdasarkan masukan dari teman-teman mereka. Selain itu, disesi ini, mereka juga mengenal kekurangan yang mereka miliki, baik menurut mereka maupun menurut orang lain, sehingga diharapkan nanti mereka dapat menghilangkan dana tau paling tidak mengurangi kelemahan yang mereka miliki agar tidak menghambat kesuksesan yang ingin mereka raih. Hal ini sesuai dengan pendapat seorang ahli perang ternama dari Cina yaitu Sun Tzu yang menyatakan bahwa jika kita mengenal diri kita dan mengenal orang lain, maka tidak usah kuatir terhadap hasil dari seratus pertempuran, karena seratus pertempuran pasti akan dimenangin (Simanjuntak, 2018).

Dengan mengetahui kekuatan dan kelemahan yang dimiliki, diharapkan peserta akan tahu apa yang menyebabkan dia sukses, sehingga dapat berupaya untuk terus menerus mempertahankan kesuksesannya. Atau mengetahui mengapai mereka gagal selama ini, kemudian mencari jalan lain agar bisa mencapai kesuksesan. Hal ini juga sesuai dengan pernyataan Albert Einsten yang mengatakan bahwa yang namanya kegilaan adalah ketika melakukan hal yang sama secara berulang-ulang tapi mengharapkan hal yang berbeda. Jika dihubungkan dengan penelitian yang telah dilakukan sebelumnya yang dilakukan oleh Profesor MS Rao (2014), masing - masing peserta merupakan pribadi yang berbeda, jadi memiliki kemampuan yang berbedabeda, oleh karena itu masing - masing harus mengerti kekurangan dan kelemahan yang dimiliki.

Tujuan lain dari sesi ini adalah supaya mahasiswa mempunyai self-efficacy yang kuat. Baron dan Bryne (2002) mendefinisikan self-efficacy sebagai evaluasi yang dilakukan oleh seseorang mengenai kemampuan dan kompetensi yang dia miliki untuk melakukan tugas, mencapai tujuan dan mengatasi hambatan yang ada. Self-efficacy berguna untuk menjaga ketekunan sehingga dapat tetap berusaha mencapai tujuan yang telah ditetapkan sebelumnya sehingga menghasilkan kinerja yang maksimal (Bandura, 1997).

Self-efficacy yang kuat dapat mengarahkan siswa untuk melakukan upaya dengan gigih dalam mencapai tujuan yang mereka mau, dimana hal ini mengakibatkan para siswa memiliki keinginan untuk mengatasi tantangan yang ada dan tidak takut terhadap kegagalan (Komarraju dan Nadler, 2013). Penelitian lain juga 
menunjukkan bahwa siswa dengan selfefficacy belajar tinggi mampu dan mau bertindak secara akademis dan belajar dengan cara motivasi yang akan membantu mereka menjadi sukses (Dogan, 2015, Feldman dan Kubota, 2015).

\section{3) My Study Plan.}

Sesi ini terbagi menjadi empat bagian yaitu impian, visi dan misi, target hidup dan rencana detail. Awalnya peserta S3D diminta untuk membayangkan mereka mau menjadi apa setelah lulus nanti. Pekerjaan apa yang mereka inginkan, posisi apa yang mereka mau, berapa gaji yang mereka harapkan dan kehidupan seperti apa yang mereka impikan ketika apa yang mereka inginkan tercapai. Kemudian setiap peserta diminta untuk membuat visi dan misi yang mereka inginkan sesuai dengan impian yang telah mereka nyatakan sebelumnya. Hal ini sesuai dengan pendapat dari Covey (2010) dalam bukunya yang berjudul tujuh kebiasaan yang dimiliki oleh orang yang efektif.

Menurut Covey, kebiasaan manusia efektif yang pertama adalah Begin with the end in mind, yang maksudnya adalah, memulai dengan melihat impian kita, jadi seperti apa kita dimasa depan. Sedangkan menurut Maxwell (2015), impian merupakan langkah awal menuju sukses, mimpi seperti peta yang akan mengarahkan seseorang untuk mencapai sukses yang dia inginkan.

Hal ini juga sesuai dengan penelitian yang dilakukan oleh Sitzmann dan Bell (2017) serta Taing dkk (2013) yang menunjukkan bahwa penetapan tujuan mempengaruhi hasil belajar dan kinerja tugas mahasiswa secara positif. Maksudnya mahasiswa yang mengetahui tujuannya secara jelas akan membuat mereka berupaya semaksimal mungkin untuk mencapainya, termasuk dengan belajar yang baik sehingga hasil belajar dan kinerja tugas mahasiswa juga baik.
Peserta S3D selanjutnya membuat goal setting berdasarkan prinsip SMART (Specific, Measurable, Achievable, Relevant and Time Framed) agar bisa mencapainya dengan lebih baik karena rencana dibuat secara mendetail. Hal ini juga sesuai dengan penelitian yang dilakukan kepada lulusan di Harvard Business School pada tahun 1979. Lulusannya diberikan pertanyaan apakah anda telah menyusun suatu rencana yang jelas, spesifik dan tertulis tentang masa depan rencana tersebut dan perencanaan tentang bagaimana merealisasikan rencana tersebut? Dari lulusan tersebut ternyata hanya 3\% yang memiliki goals yang spesifik, jelas dan tertulis, sebanyak $13 \%$ lulusan memiliki goals yang spesifik dan jelas tetapi tidak tertulis dan sisanya sebanyak $84 \%$ belum memiliki dan menyusun goals yang spesifik.

Kemudian setelah 10 tahun kemudian yaitu tahun 1989, setelah dilakukan survei lanjutan, ditemukan bahwa 13\% lulusan yang memiliki goals yang spesifik dan jelas tetapi tidak tertulis ternyata memiliki penghasilan rata - rata 2 kali lipat besarnya dari mereka yang 845 , yaitu lulusan yang belum memiliki dan menyusun goals yang spesifik, sedangkan 3\% yang memiliki goals yang spesifik, jelas dan tertulis ternyata memiliki penghasilan rata - rata yang besarnya 10 kali lipat dari pada $97 \%$ lulusan MBA lainnya. Kesimpulan dari penelitian ini adalah, seseorang yang menyusun suatu rencana yang jelas, spesifik dan tertulis tentang masa depan rencana tersebut dan perencanaan tentang bagaimana merealisasikan rencana tersebut akan lebih dapat mewujudkan rencana tersebut. 
Goal theory membagi goal setting menjadi beberapa tujuan, antara lain: learning goal, performance goal dan do your best goal (Schunk, 2008). Metode goal setting di S3D dapat dikategorikan menggunakan learning goal, karena mahasiswa membuat goal setting berdasarkan prinsip SMART. Penelitian yang dilakukan oleh Affandi dan Hastjarjo (2011) menunjukkan bahwa siswa yang diberikan learning goal yang spesifik akan menunjukkan kinerja yang lebih tinggi dibandingkan dengan performance goal dan do your best goal.

Hal ini dikarenakan learning goal akan membuat seseorang lebih mampu untuk mempertahankan kinerja yang mereka lakukan dalam waktu yang panjang (Noel \& Latham, 2006). Learning goal merupakan penentuan tujuan yang dilakukan dengan cara memfokuskan diri melalui pengembangan pengetahuan dan keterampilan tugas serta penguasaan tugas untuk mencapai tujuan yang diinginkan (Schunk, 2008), berarti learning goal lebih menitik beratkan pada proses yang dilakukan (Kanfer \& Ackerman, 1989).

Learning goal juga akan meningkatkan kemampuan metakognisi seseorang dalam menyelesaikan tugas yang harus diselesaikan (Locke \& Latham, 2006). Metakognisi secara umum dapat diartikan sebagai kemampuan untuk belajar yang meliputi proses perencanaan, pemantauan, dan evaluasi. Mahasiswa yang mempunyai goal setting akan meningkatkan motivasi mahasiswa tersebut dalam mencapainya. Hal ini sesuai dengan penelitian yang dilakukan oleh Hidayat dan Doni (2013). Goal setting yang disertai dengan motivasi berpengaruh positif terhadap prestasi (Rahayu dan Mulyana, 2015).

\section{KESIMPULAN}

Penerapan metode pembelajaran Student Soft Skill Development (S3D) melalui sesi Why S3D, Who am I dan My Study Plan sudah sesuai dengan teori dan hasil penelitian lainnya mengenai pendidikan soft skill sehingga diharapkan dapat meningkatkan soft skill mahasiswa.

\section{DAFTAR PUSTAKA}

Affandi, G. R., dan Hastjarjo, T. D. (2011). Pengaruh Tipe Penentuan Tujuan (Goal Setting) Terhadap Performansi Bahasa Inggris Siswa: dengan Efikasi Diri dan Kemampuan Awal Bahasa Inggris sebagai Kovariabel. Jurnal Psikologi, Vol. 6, No.1, 277-288.

Antariksa, Yodhia. (2011). Menyusun Sistem Performance Appraisal yang Efektif. (http://manajemenkinerja.com/).

Banerjee, J., \& Buoti, C. (2012). General Specifications of KPIs. International Telecomunnication Union.

Bandura, A. (1997). Self Efficacy: The Exercise of Control. New York: W.H. Freeman and Company.

Baron, R.A. \& Byrne, D. (2002). Social Psychology: Understanding Human Interaction. Boston: Allyn and Bacon.

Covey, Steven R. (2010). The 7 Habits of Highly Effective People. Tangerang: Binarupa Aksara Publisher.

Dogan, U. (2015). Student Engagement, Academic Self-Efficacy, and Academic Motivation as Predictors of Academic Performance. The Anthropologist, Vol.20, No.3, 553561. 
Endrotomo. (2010). Implementasi Pembelajaran Student Center Learning. Makalah disajikan dalam Seminar dalam rangka Implementasi PHK-I di STIE Triatma Mulya Badung, 28 Januari

Elfindri, dkk. (2011). Soft Skills untuk Pendidik. Jakarta: Baduose Media.

Feldman, D. B., \& Kubota, M. (2015). Hope, Self-Efficacy, Optimism, and Academic Achievement: Distinguishing Constructs and Levels of Specificity in Predicting College Grade-Point Average. Learning and Individual Differences, Vol.37, 210-216.

Gray, K., and Koncz, A. (2017). The Key Attributes Employers Seek on Students' Resumes. https://www.naceweb.org/aboutus/press/2017/the-key-attributesemployers-seek-on-studentsresumes/ (diakses Februari 2019)

Hasibuan, Malayu. (2000). Manajemen Sumber Daya Manusia. Jakarta: Bumi Aksara.

Hidayat, D. A., dan Doni, R. W. (2013). Strategi Goal Setting untuk Meningkatkan Motivasi Belajar Mahasiswa PTM Unnes Mata Kuliah Kinematika Dan Dinamika. Jurnal Penelitian Pendidikan, Vol. 30, No.1, $17-22$.

Jonathan, Sarwono. (2006). Metode Penelitian Kuantitatif dan Kualitatif. Yogyakarta: Graha Ilmu.

Kanfer, R., \& Ackerman, P.L. (1989). Motivation and Cognitive Abilities: An Integrative/ Aptitude-Treatment Interaction Approach To Skill Acquisition. Journal of Applied Psychology, Vol.74, 657-690.

Komarraju, M., \& Nadler. D. (2013). Selfefficacy and academic achievement: Why do implicit beliefs, goals, and effort regulation matter? Learning and Individual Differences, Vol.25, 67-72.

Mackes, M. (2017). Employer-Preferred Skills and Attributes. In Peck, A.
(Ed.), Engagement and Employability: Integrating Career Learning Through Co Curricular Experiences in Postsecondary Education (xi-xxxi). Washington, DC: NASPA-Student Affairs Administrators in Higher Education.

Marchand, A., Demers, A. \& Durand, P. (2005). Does Work Really Cause Distress? The Contribution of Occupational Structure and Work Organization To The Experience of Psychological Distress. Social Science \& Medicine, Vol.61, No. 1, $1-14$.

Mathur, A.k. (2017). The Role of Soft Skills in Enhancing Employability of Technical Graduates: A Study. International Journal on Emerging Technologies, Vol.8, No.1, 65-66.

Maxwell, John C (2015). Your Road Map for Success. Surabaya: MIC Publishing.

Neff, T. J., \& Citrin, J. M. (2001). Lessons from The Top. New York: Doubleday.

Noel, T., \& Latham, G. P. (2006). The Importance of Learning Goals Vs Outcome Goals for Enterpreneurs. International Journal of Enterpreneurship and Innovation, Vol.7, 213 - 220.

Rahayu, E., dan Mulyana, O.P. (2015). Hubungan antara Goal-Setting dan Motivasi Berprestasi dengan Prestasi Atlet Renang. Jurnal Penelitian Psikologi. Vol.3, No.2, 1-5.

Rao, M. S. (2014). Enhancing Employability in Engineering and Management Students Through Soft Skills. Industrial and Commercial Training, Vol.46, No.1, 42-48.

Rashidi R. A., Zaihan, N. A., and Samat, M. F. (2018). Developing Soft Skills In Students Through Co-Curriculum Activity: A Case Study Of UiTM Cawangan Kelantan. Konvensyen Kebangsaan Pemimpin Pelajar. 
Republik Indonesia (2003). Undang-undang Republik Indonesia Nomor 13 Tahun 2003 tentang Ketenagakerjaan. Jakarta: Sekretariat Negara.

Robles, M. M. (2012). Executive Perceptions Of The Top 10 Soft Skills Needed In Today's Workplace. Business Communication Quarterly, Vol.75, No.4, 453-465.

Salas Velasco, M. (2012). More than just good grades: candidates' perceptions about the skills and attributes employers seek in new graduates. Journal of Business Economics and Management, Vol.13, No.3, 499-517.

Schulz, Bernd. (2008). The Importance of Soft Skills: Education Beyond Academic Knowledge. NAWA Journal of Language and Communication, 146-154.

Schunk, D. H. (2008). Learning theories: An Educational Perspective. 5th edition. New Jersey: Pearson.

Shuayto, N. (2012). The Case For Soft Skills Development In MBA Programs. Global Conference on Business \& Finance Proceedings, Vol.7, 58-67.

Simanjuntak, D. (2018). Intisari Taktik Perang Sun Tzu. Andaliman Books.

Sitzmann, T., \& Bell, B. S. (2017). The Dynamic Effects of Subconscious Goal Pursuit on Resource Allocation, Task Performance, and Goal Abandonment. Organizational Behavior and Human Decision Processes, Vol.138, 1-14.

Stanley, T. J. (2000). The Millionaire Mind. Kansas City: Andrews McMeel Publishing.

Sugiyono. (2011). Metode Penelitian Kuantitatif, Kualitatif dan R\&D. Bandung: Alfabeta.

Sucipta, I. N. (2009). Holistik Soft Skill. Denpasar: Udayana University.

Taing et al., (2013). The Relationship Between Learning Goal Orientation, Goal Setting, and Performance: a Longitudinal Study.
Journal of Applied Social Psychology, Vol.43, No.8, 16681675.

Tseng, H., Yi, Xiang., Ye. Hsin-Te. (2018) Learning-related soft skills among online business students in higher education: Grade level and managerial role differences in selfregulation, motivation, and social skill. Computers in Human Behavior. https://doi.org/10.1016/j.chb.2018.1 1.035.

University of Missouri-St. Louis . (2012). Critical Skills and Skill Gaps 2012. http://www.umsl.edu/divisions/busin ess/files/pdfs/skillsgap13_14.pdf (diakses Februari 2019).

Watts, M. and R. K. Watts. (2009). Developing Soft Skills in Students. International Journal of Learning, Vol.15, No.12, 1-10.

Widhiarso, W. (2009). Pengembangan Soft Skills pada Mahasiswa. Makalah. Disampaikan pada Kegiatan Seminar dan Sarasehan "Evaluasi Pembelajaran Mata Kuliah Umum Kependidikan Yogyakarta FIP UNY. 